OPEN ACCESS

Check for updates

Emergency Department,

University Hospitals of Derby and

Burton NHS Foundation Trust,

Royal Derby Hospital, Derby

DE22 3NE, UK

${ }^{2}$ University of Nottingham School

of Medicine, Nottingham, UK

${ }^{3}$ Paediatric Critical Care

Department, Nottingham

University Hospitals NHS Trust,

Nottingham, UK

Correspondence to: G Johnson

graham.johnson4@nhs.net

(ORCID 0000-0001-6004-6244)

Additional material is published

online only. To view please visit

the journal online.

Cite this as: $B M J$ 2020;371:m4467 http://dx.doi.org/10.1136/bmj.m4467

Accepted: 16 November 2020

\section{Toxicological analysis of George's marvellous medicine: literature review}

\author{
Graham Johnson, ${ }^{1,2}$ Patrick Davies ${ }^{2,3}$
}

\section{ABSTRACT}

\section{OBJECTIVE}

To analyse the therapeutic effects and toxicity of the eponymous concoction described in Roald Dahl's book George's Marvellous Medicine.

DESIGN

Literature review.

SETTING

Two literature loving households in England.

PARTICIPANTS

George Kranky and grandma Kranky.

\section{MAIN OUTCOME MEASURES}

Clinical and toxic effects of the individual ingredients, checked against those listed in ToxBase, the National

Poisons Information Service's poisons database

RESULTS

The medicine contained 34 ingredients. The most common toxic effect identified on ToxBase was nausea and vomiting (16 ingredients, 47\%). Potentially life threatening effects were associated with 13 (38\%) ingredients, including depression of the central nervous system, kidney injury, convulsions, cardiac toxicity, and mucosal erosion. The effects described in the book were accurate initially but then diverted from the most likely clinical outcome (death).

\section{CONCLUSIONS}

Although Dahl ought to be applauded for his initial accuracy about the toxicology of the ingredients in George's marvellous medicine, the overall effect would be fatal catastrophic physiological collapse. Scientific exploration and experimentation should be encouraged in children, although any medicinal ingredients need to be checked for potential toxicity before being administered-to grandmas or anyone else.

\section{WHAT IS ALREADY KNOWN ON THIS TOPIC}

In George's Marvellous Medicine, a hugely popular children's book, grandma experiences sudden and major growth and invigoration after being administered the eponymous medicine

Lockdown has meant that children are spending more time at home for education

Most unintentional poisonings occur at home, and coupled with children's desire for experimentation and mimicry, the risk of attempted reproduction of George's marvellous medicine has increased

\section{WHAT THIS STUDY ADDS}

George's marvellous medicine is highly toxic

Far from experiencing major growth and invigoration, grandmas and other equally unfortunate recipients of the medicine would be at high risk of death

It would be wise for parents of budding pharmacists to remain vigilant, particularly during lockdown

\section{Introduction}

Roald Dahl is one of the most popular children's authors worldwide, with more than 200 million books published in 59 languages. ${ }^{1}$ Dahl's book George's Marvellous Medicine has been enjoyed by generations of young readers since it was first published in $1981 .^{2}$ In the 1998 edition, the verso of the contents page warns "For Doctors Everywhere,"3 but by the 2010 edition $^{4}$ the declaration had been replaced by "WARNING TO READERS: Do not try to make George's Marvellous Medicine yourselves at home. It could be dangerous." The medical import of this book was reasserted in the 2016 edition, ${ }^{5}$ which published both statements. Is the eponymous marvellous medicine medically useful, dangerous, or both? The reason for the prefaced warning is not clear, but it is possible that the disclaimer was printed in response to inadvertent harm caused by children experimenting on their grandmas.

In both the United Kingdom and the European Union, unintentional poisoning is a leading cause of accidental death in children, ${ }^{67}$ with more than 28000 children receiving treatment for poisoning in the UK each year ${ }^{8}$ and 3000 children dying across the EU annually. ${ }^{6}$ The most common place for such poisonings is the home, ${ }^{7}$ typically with smaller children exploring and putting things in their mouths, although an important proportion of unintentional and intentional poisonings are in older children, often including alcohol ingestion. During the first wave of the coronavirus disease 2019 (covid-19) pandemic, children were home schooled and relied on their parents or internet streaming services for their education, and this scenario produced the ideal conditions for children to be placed at increased risk of unintentional poisoning. ${ }^{9}$ Following lockdowns in the UK, the number of people presenting with other unintentional injuries, such as burns, has increased. ${ }^{10-12}$ Data for poisoning, however, are not yet available.

As some of the ingredients in George's marvellous medicine can be easily found in houses, the study's home educators decided that it would be interesting to concoct a similar mixture to George's but without using unsuspecting recipients such as cranky grandmas. Before embarking on our experiment, we deemed it prudent to examine the potential toxicity of the ingredients in George's marvellous medicine. We then quantified the toxicological and therapeutic potential of the medicine and compared the known effects of the ingredients with the outcomes claimed in the book.

\section{Methods}

Between March and August 2020, two researchers and their five young helpers read George's Marvellous Medicine, contemporaneously recording the ingre- 
dients and amounts in the original eponymous concoction. Reading took place in three independent teams of young readers with no communication between the groups. The ingredients were originally documented on paper using a combination of pen and pencil (one researcher does not yet have his school pen licence) and then collated in a spreadsheet (Microsoft Excel 2010, Microsoft, WA).

We then cross referenced the ingredients with the relevant entries in ToxBase, the National Poisons Information Service's poisons database. ${ }^{13}$ When we could not find exact matches, we chose the nearest approximation (for example, purple pills to treat hoarse horses in the book were matched to the pale purple chewable tablets of phenylbutazone, a nonsteroidal anti-inflammatory drug used to treat "the strangles," an equine disease ${ }^{14}$ ). We graded the severity of any potential effects. As poisoning shows a dose-response, we presumed that a moderate dose had been administered to grandma.

According to the National Health Service Health Research Authority, ${ }^{15}$ our study would be defined as research (in that findings are generalisable to any child who wishes to recreate the marvellous medicine) but does not require ethical approval. We only present descriptive statistics.

Owing to the varied ages and reading skills of the reading teams, we wrote three versions of the paper (see supplementary files 1 and 2 for the other two). This main version is appropriate for undergraduate reading age level, whereas the other versions are appropriate for reading ages 9-10 years (grade 4.8) and 14-15 years (grade 9.6), based on the Flesch-Kincaid method. ${ }^{16}$

\section{Patient and public involvement}

Representatives of the parents and children of St Chad's Primary School were consulted about the study. The child PPI members agreed that attempts at reproducing the medicine, or concocting their own with inspiration from the original, was an attractive proposition. Several parent PPI members reported experience of finding such mixtures being created or having to take measures to prevent them from being created in their own homes.

\section{Results}

All 95 pages of the story were read. Thirty four different ingredients were identified-10 from the bathroom, four from the bedroom, five from the laundry room, six from the kitchen, five from the shed (and a further one after heating, bringing the total to six), and three from the garage. No discrepancies were found between the three independent groups of readers, giving a $\kappa$ statistic of 1.0 .

The most common potential symptom was nausea and vomiting, with this listed as a common effect for 16 (47\%) ingredients, closely followed by depression of the central nervous system for 13 (38\%) ingredients (five (15\%) caused by the effects of ethanol). Eleven (32\%) ingredients were linked to diarrhoea and six (18\%) to cardiac involvement (myocarditis or arrhythmias). Four
(12\%) caused foaming or hypersalivation, or both, and four (12\%) caused gastrointestinal tract ulceration and haematemesis. Seven (21\%) caused lung injury and four $(12 \%)$ caused seizures (fig 1$)$.

Five (15\%) of the ingredients were foodstuffs found in the kitchen which, although particularly spicy, are not considered too toxic. Although these ingredients might have contributed to vomiting in high doses, only the "extra hot" chilli sauce is listed in Toxbase.

Treatments for this multivariate poisoning were complex and would require immediate high level care. Treatments included (but were not limited to) airway protection, management of seizures and arrhythmias, antidotes, lipid infusions, and haemofiltration.

\section{Discussion}

Our findings suggest that far from being marvellous, George's medicine is in fact incredibly toxic. Fortunately, the restrictions imposed by the UK lockdown ensured the researchers' parents were safe from sample concoctions. It is known that mimicry plays a role in poisoning in children, ${ }^{17}$ and both increased time at home and the ongoing search for a treatment for covid-19 might inspire budding scientists to search for a cure themselves. George's Marvellous Medicine could be used as a starting point for any future pharmaceutical engineers.

The account given of the likely effects of ingesting the medicine was extremely accurate (allowing for some poetic licence). Grandma initially "shot up whoosh into the air" and when she landed she shouted suddenly "My stomach's on fire!" This immediate effect was likely due to the high level of capsaicin-however, ingredients such as sheep dip (organophosphate), dark tan shoe polish (white spirit, heavy naphtha, trimethylbenzene), and floor polish (heavy naphtha) cause mucosal erosion and are likely to have contributed to severe gastric dyspepsia. George's treatment using a jug of water is unlikely to have been helpful and might have increased the risk of later aspiration as well as of later cardiogenic shock due to excess preload if grandma had developed myocarditis.

Subsequently grandma begins to swell, before developing a puncture and deflating. With four ingredients causing foaming, gastrointestinal bloating is to be expected. Puncture, however, was not a recommended treatment in ToxBase.

Thereafter “Grandma's body gave a sudden sharp twist and a sudden sharp jerk and she flipped herself clear out of the chair." Four of the ingredients (sheep dip, engine oil, antifreeze, and grease) cause convulsions or myoclonic jerks, or both, so again Dahl's research was accurate. Although it is highly unlikely that grandma would have "landed neatly on her two feet on the carpet," as described.

From this point the account of the effects of the medicine diverges from reality. Not only does grandma no longer feel any ill effects, but she grows to the size of a house, breaking through the roof. None of the 34 ingredients are documented as having any individual effect on growth. ${ }^{18}$ 


\begin{tabular}{|c|c|c|c|c|c|c|c|c|c|c|}
\hline & Nausea & Vomiting & Diarrhoea & Foaming & $\begin{array}{l}\text { Kidney } \\
\text { injury }\end{array}$ & $\begin{array}{c}\text { CNS } \\
\text { depression }\end{array}$ & Convulsions & Erosion & $\begin{array}{l}\text { Lung } \\
\text { injury }\end{array}$ & $\begin{array}{l}\text { Cardiac } \\
\text { toxicity }\end{array}$ \\
\hline \multicolumn{11}{|c|}{ Golden gloss hair shampoo } \\
\hline \multicolumn{11}{|l|}{ Toothpaste } \\
\hline \multicolumn{11}{|l|}{ Superfoam shaving soap } \\
\hline \multicolumn{11}{|c|}{ Vitamin enriched face cream } \\
\hline \multicolumn{11}{|l|}{ Scarlet nail varnish } \\
\hline \multicolumn{11}{|l|}{ Hair remover, legs } \\
\hline \multicolumn{11}{|c|}{ Dishworth's dandruff cure } \\
\hline \multicolumn{11}{|c|}{ Brillident false teeth cleaner } \\
\hline \multicolumn{11}{|c|}{ Nevermore ponking deodorant } \\
\hline \multicolumn{11}{|l|}{ Liquid paraffin } \\
\hline \multicolumn{11}{|l|}{ Helga's hairset } \\
\hline \multicolumn{11}{|c|}{ Perfume "Flowers of turnips" } \\
\hline \multicolumn{11}{|c|}{ Pink plaster powder } \\
\hline \multicolumn{11}{|l|}{ Lipsticks } \\
\hline \multicolumn{11}{|c|}{ Superwhite washing powder } \\
\hline \multicolumn{11}{|l|}{ Waxwell floor polish } \\
\hline \multicolumn{11}{|l|}{ Flea powder for dogs } \\
\hline \multicolumn{11}{|l|}{ Canary seed } \\
\hline \multicolumn{11}{|l|}{ Dark tan shoe polish } \\
\hline \multicolumn{11}{|l|}{ Gin } \\
\hline \multicolumn{11}{|l|}{ Curry powder } \\
\hline \multicolumn{11}{|l|}{ Mustard powder } \\
\hline \multicolumn{11}{|l|}{ "Extra hot" chilli sauce } \\
\hline \multicolumn{11}{|l|}{ Black peppercorns } \\
\hline \multicolumn{11}{|l|}{ Horseradish sauce } \\
\hline \multicolumn{11}{|c|}{ Fowl pest powder to mix with feed } \\
\hline Purple pills for hoarse $h$ & & & & & & & & & & \\
\hline Thick yellowish liquid, $\mathrm{f}$ & & & & & & & & & & \\
\hline Sheep dip & & & & & & & & & & \\
\hline Pig pills, swine sickness & & & & & & & & & & \\
\hline Engine oil & & & & & & & & & & \\
\hline Antifreeze & & & & & & & & & & \\
\hline Grease & & & & & & & & & & \\
\hline Dark brown gloss paint & & & & & & & & & & \\
\hline
\end{tabular}

Fig 1 | Ingredients of George's marvellous medicine and the likely clinical effects of ingestion. CNS=central nervous system

A more realistic version of the clinical course is considerably more sombre and would need some time to develop. The best case scenario is that immediate, intractable, and vigorous vomiting would occur in time to prevent systemic absorption of a fatal dose of toxic ingredients. However, the highly caustic nature of the medicine would almost certainly have resulted in immediate and severe oesophageal burns, potentially leading to a catastrophic oesophageal-aortic erosion and a lifetime of dysphagic complications.

A pessimistic, but more realistic, scenario would be the high likelihood of rapid drowsiness and coma from the excessive amounts of alcohol consumed together with the other central nervous system depressants. The combination of vomiting and reduced conscious level would likely lead to aspiration pneumonitis, if not complete airway obstruction and suffocation.

Should grandma have survived this physiological insult, then seizures and respiratory depression would add to the risk of death from hypoxia. Myocarditis and arrhythmias would probably follow, along with gastrointestinal erosions, upper gastrointestinal haemorrhage, and gastrointestinal perforation. If these did not prove fatal, disseminated intravascular coagulopathies and irreversible hepatorenal failure would result. A suggested treatment algorithm has been provided, should a grandma (or any other unfortunate person) be administered George's marvellous medicine (fig 2).

For an inquisitive child such as George, the Kranky's dusty old shed and garage provided a wealth of 
ingredients to choose from, as these were where his father, a farmer, stored the most dangerous substances. The shed had the odd assortment of "thick yellowish liquid," for cows (ivermectin and milbemycin) and sheep dip (organophosphate), and the garage provided engine oil and antifreeze (ethylene glycol), as well as windscreen washer fluid, which typically contains methanol, a toxic alcohol (and occasionally small amounts of ethylene glycol).

Most of the ingredients found in a typical home cause relatively mild effects (chiefly gastrointestinal). The most dangerous household items found at George's were "superwhite” washing powder, "waxwell” floor polish, and the "brown shoe polish," all of which are available in many modern households. Liquid laundry capsules are common sources of childhood toxicity ${ }^{19}$; they can be dangerous even without ingestion as bursting a capsule can result in forceful injection into the eye, with major injury to the cornea.

Because of the extra time spent by children at home during lockdown, and their innate desire to experiment and explore, it is vital that parents are well informed to ensure their children's safety. Much progress has been made in safety around the home since the

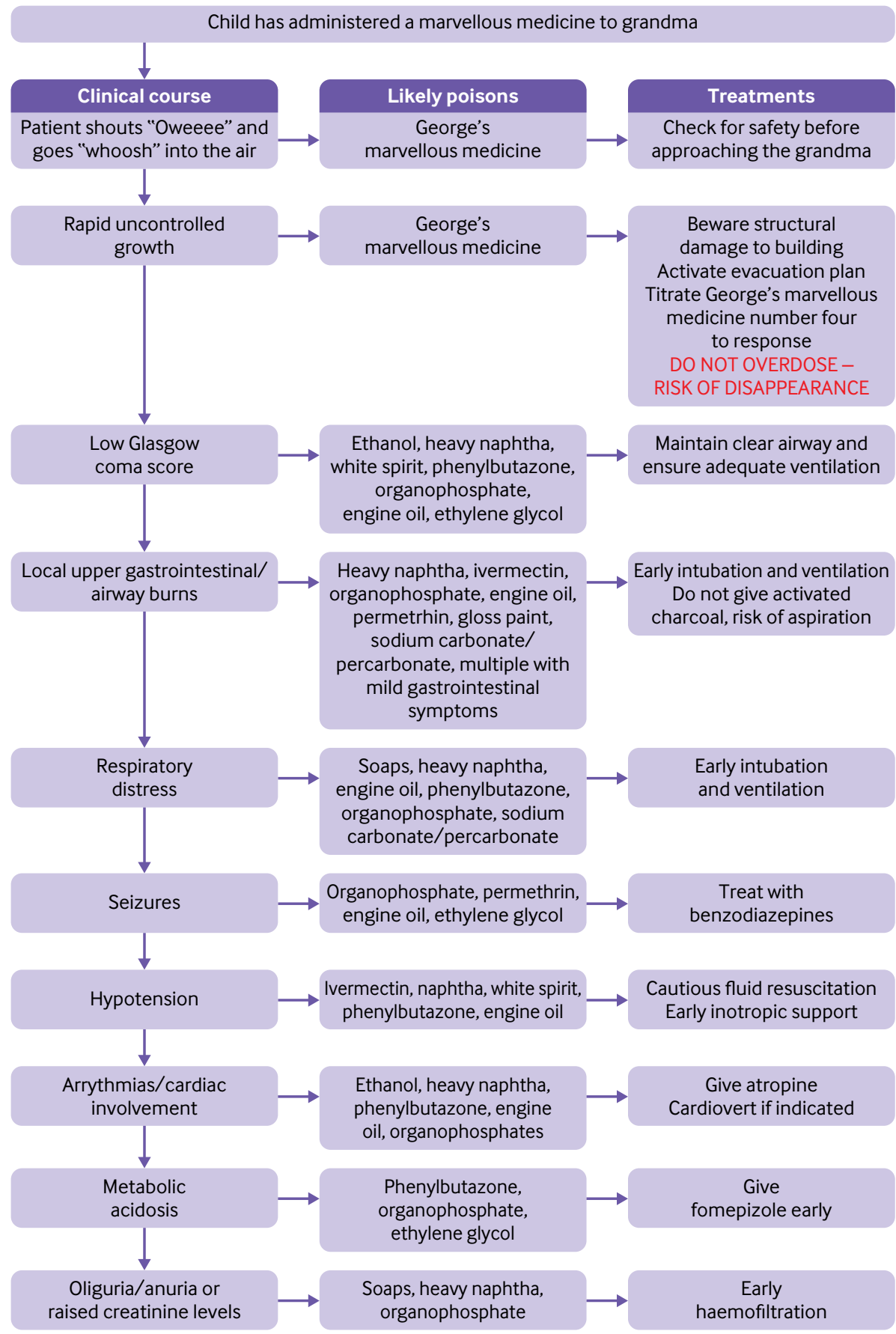

Fig 2 | Treatment algorithm should grandma or any unfortunate person be administered George's marvellous medicine 
publication of George's Marvellous Medicine in 1981, with child proof packaging, clearer labelling, and bans on the most dangerous products. The Royal Society for the Prevention of Accidents produces a helpful factsheet ${ }^{20}$ about the most potentially dangerous items in the home, and, crucially, a checklist ${ }^{21}$ for parents to serve as an aide memoire. Importantly, this checklist contains a warning to "NEVER mix cleaning products." Children have always been fascinated by potions with magical properties, which is consistently represented in children's literature. ${ }^{22}$ The current lockdown generation of children might well be as influenced by the potions of Harry Potter as by George's marvellous medicine. Some ingredients used in magical potions are readily available in British gardens (eg, foxglove, wormwood, mistletoe, elder) and parents should be extra cautious about their budding pharmacists.

\section{Limitations of this study}

Our study has limitations. Firstly, we did not combine the ingredients as described in the book so are unable to comment on potential chemical interactions. Secondly, although the quantities of each ingredient used are in most cases documented, the precise dose taken by grandma is not, leading to some assumptions about the effects. Thirdly, our study is an in vitro extrapolation; we did, however, judge it unlikely that an in vivo study would pass ethical review. Fourthly, we did not assess the effects of heat on the medicine. Although this process is usually used to catalyse chemical reactions, it most likely would have only made the mixture more concentrated. Fifthly, the effects of chanting and dancing ("And suddenly, George found himself dancing around the steaming pot, chanting strange words"), despite notable effects in rainmaking, ${ }^{23}$ are unlikely to have materially affected the physical properties and physiological effects of the medicine. Finally, we did not analyse the contents of medicines numbers two, three, and four because the contents are not as explicitly detailed, but they are broadly similar to those of medicine number one, the eponymous concoction.

When George attempted to reassure grandma that the medicine will do her good, she prophetically exclaims “Doing me good? It's killing me!” Experienced healthcare professionals know to take such proclamations seriously.

\section{Conclusion}

Although we applaud Dahl's initial accuracy about the toxicological effects of the ingredients in George's marvellous medicine, the overall outcome for grandma would be fatal catastrophic physiological collapse. It is unlikely that children will recreate each step in the making of a marvellous-type medicine, but it is worth being cautious as some of the household ingredients used by George are considerably dangerous and commonly cause severe morbidity in children. Although parents might encourage scientific exploration and experimentation in their children, it would be wise to check any medicinal ingredients for potential toxicity before use.

For their invaluable contribution to data gathering for this study and for reviewing and editing the age appropriate manuscripts, we thank Max Davies, Beatrix Davies, and Casper Davies (West Bridgford School, Nottingham, UK) and Harry Johnson and Edward Johnson (St Chad's Primary School, Lichfield, UK). Without their hard work and resilience during lockdown this work would not have been possible.

Contributors: GJ and PD motivated, focused, encouraged, and cajoled the reading groups. GJ took receipt of the ingredients list from MD, $\mathrm{BD}, \mathrm{CD}, \mathrm{HJ}$, and EJ, searched the corresponding Toxbase entries, and drafted and edited the main paper. PD developed the hypothesis and edited the manuscript. GJ and PD act as guarantors.

Funding: No external funding. The authors funded the books.

Competing interests: GJ has completed the ICMJE uniform disclosure form at www.icmje.org/coi_disclosure.pdf and both authors declare: no support from any organisation for the submitted work; no financial relationships with any organisations that might have an interest in the submitted work in the previous three years; no other relationships or activities that could appear to have influenced the submitted work.

Ethical approval: Not required. No consent has been sought from George Kranky, the original maker of the medicine, or his parents. The barrier to this chiefly being their fictional nature and therefore inability to give valid consent.

Data sharing: Technical appendix and dataset are available from the corresponding author.

G) affirms that the manuscript is an honest, accurate, and transparent account of the study being reported; no important aspects of the study have been omitted; that any discrepancies from the study as planned have been explained.

Dissemination to participants and related patient and public communities: In addition to the main manuscript, two additional versions have been provided as additional files to ensure that the important study findings are more accessible for independent reading by a young audience.

Provenance and peer review: Not commissioned; externally peer reviewed.

This is an Open Access article distributed in accordance with the Creative Commons Attribution Non Commercial (CC BY-NC 4.0) license, which permits others to distribute, remix, adapt, build upon this work non-commercially, and license their derivative works on different terms, provided the original work is properly cited and the use is noncommercial. See: http://creativecommons.org/licenses/by-nc/4.0/.

1 Dahl R. com - About Us. https://www.roalddahl.com/global/aboutus(accessed 2 November 2020)

Dahl R. George's Marvellous Medicine . Jonathan Cape, 1981. Dahl R. George's Marvellous Medicine . Puffin, 1998.

Dahl R. George's Marvellous Medicine . Jonathan Cape, 2010. Dahl R. George's Marvellous Medicine. Puffin, 2016.

6 European Child Safety Alliance. Childhood Poisoning, 2009.

7 European Child Safety Alliance. Child Safety Report

Cards 2012;31:32. https://www.childsafetyeurope.org/reportcards.

8 Royal Society for the Prevention of Accidents. Accidents to Children. https://www.rospa.com/home-safety/advice/accidents-tochildren\#poisoning.

9 Williams T, Mayhew M, Lagou M, et al. Coronavirus and homeschooling in Great Britain: April to June 2020. 22 July 2020. https://www.ons.gov.uk/releases/ coronavirusandhomeschoolingingreatbritainapriltojune 2020.

10 Brewster CT, Choong J, Thomas C, Wilson D, Moiemen N. Steam inhalation and paediatric burns during the COVID-19 pandemic. Lancet 2020;395:1690. doi:10.1016/S0140-6736(20)31144-2.

11 D’Asta F, Choong J, Thomas C, et al. Paediatric burns epidemiology during COVID-19 pandemic and 'stay home' era. Burns 2020;46:1471-2. doi:10.1016/j.burns.2020.06.028.

12 Lewins I. Advice for treating burns after sharp rise in cases in children 2020. https://www.uhdb.nhs.uk/latest-news/advice-for-treating burns-after-sharp-rise-in-cases-in-children-8779/ (accessed 30 July 2020).

13 National Poisons Information Service. Toxbase, 2020

14 The British Horse Society. Strangles: The British Horse Society. https://www.bhs.org.uk/advice-and-information/ horse-health-and-sickness/strangles?fbclid= IwAROGNr8WozHgfOasRJ0svtceZE5xKSq2mmlTevhfaMESTgw5oCN Bhgkx97Q (accessed 2 August 2020). 2020. 
15 Health Research Authority. Is My Study Research. http://www.hradecisiontools.org.uk/research/index.html (accessed 2 August 2020).

16 Readable. The Flesch Reading Ease and Flesch-Kincaid Grade Level. https://readable.com/blog/the-flesch-reading-ease-and-fleschkincaid-grade-level (accessed 25 November 2020).

17 Rodgers GB, Franklin RL, Midgett JD. Unintentional paediatric ingestion poisonings and the role of imitative behaviour. Inj Prev 2012;18:103-8. doi:10.1136/injuryprev-2011-040008.

18 NuBest Tall https://www.nubest com/nubest-tall-60-capsulesgrowth-height-nanometer-calcium-242508/?utm_source=GoogleSEM\&utm_medium=Nubest_Tall\&utm_content=Products\&utm_ campaign=BR-FULL-GB-FULL-0000-1307-growth-pills-NDT\&gclid=E AlalQobChMlmrv9gL_46gIV34BQBh38qAzLEAAYASAAEglsFvD_BwE (accessed 2 August 2020)

19 Royal Society for the Prevention of Accidents. Liquid laundry capsules: RoSPA. https://www rospa.com/Home-Safety/Advice/ Product/liquid-laundry-capsules.aspx (accessed 31 July 2020).

20 Royal Society for the Prevention of Accidents. TAKE ACTION TODAY, PUT THEM AWAY! In: Accidents RSftPo, ed. Royal Society for the Prevention of Accidents, 2017:1-5. https://www.rospa.com/rospaweb/docs/ advice-services/home-safety/take-action-factsheet.pdf.

21 Royal Society for the Prevention of Accidents. TAKE ACTION TODAY, PUT THEM AWAY! A Safety Checklist for Parents. In: Accidents RSftPo, ed. Royal Society for the Prevention of Accidents, 2017. https://www. rospa.com/rospaweb/docs/advice-services/home-safety/safetychecklist-for-parents.pdf.

22 Alward A. Children's Book of the Month: The Potion Diaries - Amy Alward 2015. https://blog.whsmith.co.uk/childrens-book-of-themonth-the-potion-diaries-amy-alward/\#: :text=There\%20have $\% 20$ been $\% 20$ some\%20great,just $\% 20$ to\%20name\%20a\%20few.

23 Rainmaking (ritual). https://en.wikipedia.org/wiki/Rainmaking (ritual). (accessed 1 August 2020).

Supplementary information: article for reading level age 9-10 years

Supplementary information: article for reading level age 14-15 years 